\title{
Pharmacokinetic Study on Hirsutine and Hirsuteine in Rats Using UPLC-MS/MS
}

\author{
Aixia Han ${ }^{1}$, Guanyang $\mathrm{Lin}^{2}$, Jinzhang $\mathrm{Cai}^{3}$, Qing $\mathrm{Wu}^{2}$, Peiwu Geng ${ }^{1}$, Jianshe $\mathrm{Ma}^{4}$, \\ Xianqin Wang $^{4 *}$ and Chongliang Lin $^{2^{*}}$ \\ ${ }^{1}$ Department of Pharmacy, The People's Hospital of Lishui, Lishui 323000, China \\ ${ }^{2}$ Department of Pharmacy, The First Affiliated Hospital of Wenzhou Medical University, Wenzhou 325000, China \\ ${ }^{3}$ The Second Affiliated Hospital and Yuying Children's Hospital of Wenzhou Medical University, Wenzhou 325027, China \\ ${ }^{4}$ Analytical and Testing Center, School of Pharmaceutical Sciences, Wenzhou Medical University, Wenzhou 325035, China
}

Received: 29 August 2017; accepted: 03 November 2017

\begin{abstract}
An ultra-performance liquid chromatography-tandem mass spectrometry (UPLC-MS/MS) method was established to determine hirsutine and hirsuteine in rat plasma. Pharmacokinetics of hirsutine and hirsuteine in rats after intravenous or oral administration has been investigated using this developed UPLC-MS/MS method, and bioavailability of the two drugs was calculated. Diazepam was used as internal standard, and UPLC BEH column $(2.1 \mathrm{~mm} \times 50 \mathrm{~mm}, 1.7 \mu \mathrm{m})$ was used at temperature of $40{ }^{\circ} \mathrm{C}$. The mobile phase was composed of acetonitrile and water (containing $0.1 \%$ formic acid) at a gradient elution flow rate of $0.4 \mathrm{~mL} / \mathrm{min}$. Nitrogen was used as desolvation gas $(800 \mathrm{~L} / \mathrm{h})$ and conical gas $(50 \mathrm{~L} / \mathrm{h})$. The multiple reaction monitoring $(\mathrm{MRM})$ model was applied to quantitatively analyze hirsutine $\mathrm{m} / \mathrm{z} 369 \rightarrow 226$, hirsuteine $\mathrm{m} / \mathrm{z} 367 \rightarrow 169.9$, and diazepam (internal standard) $\mathrm{m} / \mathrm{z} 285.1 \rightarrow$ 193.3. Rat plasma samples were deproteinized using acetonitrile prior to UPLC-MS/MS analysis. Within the concentration range of 1-200 ng/mL, the linearity of hirsutine and hirsuteine in plasma was good $(r>0.995)$, and the lower limit of quantitation was $1 \mathrm{ng} / \mathrm{mL}$. Relative standard deviations of intra-day precision for hirsutine and hirsuteine were $\leq 6.1 \%$ and $\leq 5.9 \%$, respectively, and those of inter-day precision were $\leq 6 \%$ and $\leq 7.7 \%$. Accuracy for hirsutine and hirsuteine ranged between $92.3 \%$ and $104.8 \%$. Bioavailability of hirsutine and hirsuteine was $4.4 \%$ and $8.2 \%$, respectively. The method is sensitive and fast with good selectivity and was successfully applied in the pharmacokinetic studies after intravenous and oral administration of hirsutine and hirsuteine.
\end{abstract}

Keywords: Hirsutine; hirsuteine; pharmacokinetics; UPLC-MS/MS; bioavailability

\section{Introduction}

Uncaria rhynchophylla is a commonly used traditional Chinese medicine, belonging to Uncaria schreber of rubiaceae [1, 2]. Pharmacological research indicates that $U$. rhynchophylla has an antagonistic effect on $\mathrm{Ca}^{2+}$, can inhibit internal flow and release of $\mathrm{Ca}^{2+}$, and thus poses a strong inhibition effect on the cardiovascular system and significantly decreasing blood pressure [3]. It furthermore has significant effects of nerve block, infiltration anaesthesia, and intraspinal anesthesia [4, 5]. Moreover, it exerts significant inhibition effects on synaptic transmission process of central nervous system and anti-epilepsy [6, 7]. It can be applied to reduce blood pressure, for calming, and as sleeping-aid and spasmolytic. Indole alkaloid is the main effective component of U. rhynchophylla plants, mainly including rhynchophylline, isorhynchophylline, corynoxeine, isocorynoxeine, corynoxine, corynoxine $\mathrm{B}$, hirsutine, hirsuteine, corynantheine, and dihydrogen coinine $[8,9]$.

The study of pharmacokinetics quantitatively investigates the absorption, distribution, metabolism, and excretion (ADME) of drugs in vivo, as well as the underlying mechanism, interaction within complex drug system, and drug effect material basis $[10,11]$. Hirsutine and hirsuteine are the two main active components of $U$. rhynchophylla. Their pharmacological effects are closely related to the variation in vivo and distribution characteristics. To study the absorption and distribution of hirsutine and hirsuteine in vivo, it is necessary to systematically investigate the pharmacokinetics, which provides a theoretical basis for drug research and development. Thus, the pharmacokinetics of hirsutine and hirsuteine is very important for the clinical application of $U$. rhynchophylla.

\footnotetext{
* Authors for correspondence: lankywang@163.com, linchongliang2012@163.com
}

So far, several studies reported the pharmacokinetics of rhynchophylline, isorhynchophylline, corynoxeine, and isocorynoxeine [12-21]. However, few studies reported the pharmacokinetics of hirsutine and hirsuteine. Wu et al. [15] established an ultra-performance liquid chromatography-tandem mass spectrometry (UPLC-MS/MS) method to simultaneously measure rhynchophylline and hirsutine in rat plasma and also investigated the pharmacokinetics of rhynchophylline and hirsutine following oral administration of uncaria extractives $(1000 \mathrm{mg} / \mathrm{kg}$, equivalent to $0.82 \mathrm{mg} / \mathrm{kg}$ rhynchophylline and $3.47 \mathrm{mg} / \mathrm{kg}$ hirsutine). The areas under the curves (AUCs) of rhynchophylline and hirsutine were $222 \pm 94$ and $1406 \pm 758 \mathrm{~min} \cdot \mathrm{ng} / \mathrm{mL}$, and halflives $\left(t_{1 / 2}\right)$ were $81 \pm 56 \mathrm{~min}$ and $94 \pm 37 \mathrm{~min}$, respectively. Kashia et al. [16] investigated the pharmacokinetics of indole and oxindole alkaloids of $U$. rhynchophylla plants in rat plasma and brain after oral administration of the traditional Japanese drug Yokukansan, by establishing liquid chromatography (LC) MS/MS detection methods for seven uncaria alkaloids (including rhynchophylline, isorhynchophylline, corynoxeine, isocorynoxeine, hirsutine, hirsuteine, and geissoschizine methyl ether). After oral administration of Yokukansan, rhynchophylline, hirsutine, hirsuteine, and geissoschizine methyl ether were detected in the plasma, with half-lives of $1.4 \mathrm{~h}, 3.4 \mathrm{~h}, 1.9-3.6 \mathrm{~h}$, and 1.5-2.0 h, respectively. In the rat brain, only geissoschizine methyl ether was detected, indicating it as an important component for the pharmacologic action of Yokukansan. However, none of these studies reported the pharmacokinetics of hirsutine and hirsuteine after intravenous administration.

Compared to LC-MS/MS, UPLC-MS/MS is more sensitive, offering significant advantages in the investigation of pharmacokinetics of chemical drugs [22, 23]. Furthermore, a powerful separation and analysis capacity is applicable to analyze in vivo

This is an open-access article distributed under the terms of the Creative Commons Attribution-NonCommercial 4.0 International License (https://creativecommons.org/licenses/by-nc/4.0/), which permits unrestricted use, distribution, and reproduction in any medium for non-commercial purposes, provided the original author and source are credited, a link to the CC License is provided, and changes - if any - are indicated. 
metabolites of complicated traditional Chinese medicine components and complex compound systems. In this study, a UPLC-MS/MS detection method was built to measure the plasma concentrations of hirsutine and hirsuteine. Using this method, pharmacokinetics of the two drugs after intravenous and oral administration were investigated, and bioavailability was calculated.

\section{Materials and Methods}

Chemical and Animal. Hirsutine (purity $>98 \%$, Figure 1a) and hirsuteine (purity $>98 \%$, Figure $1 \mathrm{~b}$ ) were purchased from Chengdu Mansite Pharmaceutical Co., Ltd. Diazepam (internal standard, purity $>98 \%$, Figure 1c) was purchased from National Institutes for Food and Drug Control. HPLC-grade acetonitrile and methanol were purchased from Merck (Darmstadt, Germany). Ultrapure water was made with a Millipore Milli-Q water system (Bedford, MA, USA). Sprague-Dawley (SD) rats (200-220 g) were purchased from the Animal Experimental center of Wenzhou Medical University.

Equipment. The AQUITY I-Class UPLC and XEVO TQSmicro triple quadrupole mass spectrometer (Waters Corp, Milford, MA, USA) was used in this study. Masslynx 4.1 software (Waters Corp.) was used to collect data and to control the equipment.

UPLC BEH C18 column $(2.1 \mathrm{~mm} \times 50 \mathrm{~mm}, 1.7 \mu \mathrm{m}$, Waters, USA) was used to analyze hirsutine and hirsuteine in the plasma, and the temperature was set to $40{ }^{\circ} \mathrm{C}$. The mobile phase was composed of acetonitrile and water (containing $0.1 \%$ formic acid) using gradient elution. The flow rate was set at $0.4 \mathrm{~mL} / \mathrm{min}$, and elution time was $4 \mathrm{~min}$. The gradient elution was set as follows: $0-0.2 \mathrm{~min}$, acetonitrile $10 \% ; 0.2-1.5 \mathrm{~min}$, acetonitrile $10 \%-80 \%$; $1.5-2.0 \mathrm{~min}$, acetonitrile $80 \%$; $2.0-2.5 \mathrm{~min}$, acetonitrile $80 \%-10 \%$; and $2.5-4.0 \mathrm{~min}$, acetonitrile $10 \%$.

Nitrogen was used as both desolvation gas $(800 \mathrm{~L} / \mathrm{h})$ and conical gas $(50 \mathrm{~L} / \mathrm{h})$. Capillary voltage was set to $1.5 \mathrm{kV}$, ion source temperature was $150{ }^{\circ} \mathrm{C}$, and desolvation temperature was $400{ }^{\circ} \mathrm{C}$. The multiple reaction monitoring (MRM) model was applied to quantitatively analyze hirsutine $\mathrm{m} / \mathrm{z} 369.2 \rightarrow$ 226.0, hirsuteine $\mathrm{m} / \mathrm{z} 367 \rightarrow 169.9$, and diazepam (internal standard) $\mathrm{m} / \mathrm{z} 285.1 \rightarrow 193.3$.

Preparation of Standard Working Solutions. Stock solutions of hirsutine $(1.0 \mathrm{mg} / \mathrm{mL})$, hirsuteine $(1.0 \mathrm{mg} / \mathrm{mL})$, and diazepam $(1.0 \mathrm{mg} / \mathrm{mL})$ were prepared with methanol-water at a ratio of 50:50 (v/v). A series of standard working solutions with different concentrations was prepared by diluting stock solutions with methanol. All solutions were stored at $4{ }^{\circ} \mathrm{C}$.

Preparation for Standard Curve. Blank rat plasma was added with appropriate working solutions of hirsutine and hirsuteine to prepare samples with concentrations of $1,5,10,20,60,100$, and $200 \mathrm{ng} / \mathrm{mL}$ (concentration range within 1-200 ng/mL). With the identical method, samples for quality control (QC) at concentrations of 2, 45, and $190 \mathrm{ng} / \mathrm{mL}$ were prepared.
Sample Processing. In a $1.5 \mathrm{~mL}$ centrifuge tube, $100 \mu \mathrm{L}$ of plasma sample was added, further added with $200 \mu \mathrm{L}$ of acetonitrile (containing internal standard diazepam, $50 \mathrm{ng} / \mathrm{mL}$ ), mixed with a vortexer, and centrifuged at 13,000 rpm for $10 \mathrm{~min}$ at $4{ }^{\circ} \mathrm{C}$. Supernate $(100 \mu \mathrm{L})$ was transferred into a liner pipe in a vial, and injection volume was $2 \mu \mathrm{L}$.

Method Validation. Method validation was conducted according to the Analytical Procedures and Methods Validation for Drugs and Biologics made by the Food and Drug Administration (FDA) [24]. The validation work included selectivity, matrix effect, linearity, precision, accuracy, recovery, and stability.

Selectivity of the UPLC-MS/MS method was evaluated by detecting six lots of blank plasma, blank plasma spiked with hirsutine, hirsuteine and internal standard (diazepam), and plasma samples.

The standard solutions (concentration range between 1 and $200 \mathrm{ng} / \mathrm{mL}$ ) were detected under the same conditions as plasma samples, and standard curves (peak area versus concentration) were plotted to evaluate linearity.

Precision and accuracy of the method were evaluated by measuring concentrations of three plasma samples for six times. Precision was expressed as relative standard deviation (RSD). Intra-day and inter-day precisions were confirmed by measuring the QC samples within three continuous days. Accuracy was evaluated by the coincidence level between average concentrations of the QC samples and actual values within three continuous days. The intra-day and inter-day precisions should not exceed $15 \%$, and the accuracy should be within $\pm 15 \%$.

The recovery was evaluated by comparing the peak area of extracted QC samples with that of reference QC solutions.

The matrix effect was evaluated via comparison of peak area between standard solutions spiked into blank plasma after protein precipitation by acetonitrile and the corresponding concentrations of standard solutions.

Stabilities of hirsutine and hirsuteine in plasma were analyzed by storing the QC samples (at three concentrations) under different storage conditions, including short-term stability $(2 \mathrm{~h}$ at room temperature), long-term stability $\left(-20{ }^{\circ} \mathrm{C}\right.$ for 30 days), and freeze-thaw stability (continuous freeze-thaw for three times, from $-20{ }^{\circ} \mathrm{C}$ to room temperature).

Pharmacokinetic Study. Diet was prohibited for $12 \mathrm{~h}$ before the experiment while water was freely available. Twenty-four SD rats (200-220 g) were numbered as 1-24 and divided into four groups. Rats 1-6 and rats 7-12 were intravenous administrated with hirsuteine $(1.0 \mathrm{mg} / \mathrm{kg})$ and hirsutine $(1.0 \mathrm{mg} / \mathrm{kg})$, respectively. Rats $13-18$ and rats $19-24$ were orally administered with hirsuteine $(5 \mathrm{mg} / \mathrm{mL})$ and hirsutine $(5 \mathrm{mg} / \mathrm{mL})$, respectively. Blood $(0.3 \mathrm{~mL})$ was drawn from the caudal vein of rats $1-12$ at $0.0333,0.25,0.5,1,2,4$, $6,8,12$, and $24 \mathrm{~h}$ after intravenous administration and of rats $13-24$ at $0.08333,0.25,0.5,1,2,4,6,8,12$, and $24 \mathrm{~h}$ after oral administration. The blood was centrifuged at $13,000 \mathrm{rpm}$
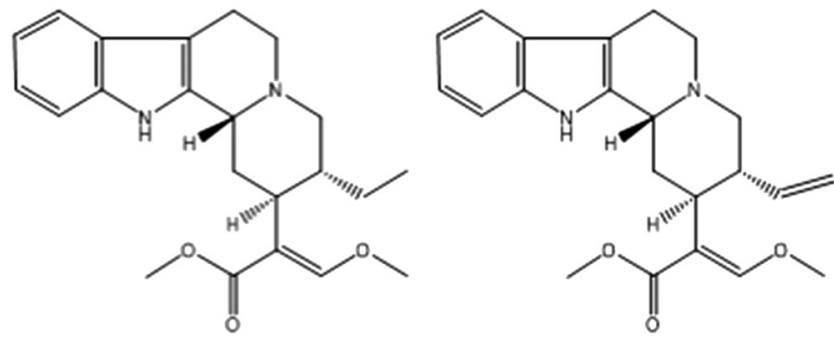<smiles>CN1C(=O)CN=C(c2ccccc2)c2cc(Cl)ccc21</smiles>

Figure 1. Chemical structure of hirsutine (a), hirsuteine (b), and diazepam (internal standard, c) 
for $10 \mathrm{~min}$ at $4{ }^{\circ} \mathrm{C}$, and $100 \mu \mathrm{L}$ of the supernate was transferred into a $1.5 \mathrm{~mL}$ centrifuge tube and stored at $-20^{\circ} \mathrm{C}$.

AUC, mean residence time (MRT), clearance rate (CL), apparent distribution volume $(\mathrm{V})$, maximum plasma concentration $\left(C_{\max }\right)$, and half-life $\left(t_{1 / 2}\right)$ were analyzed using a non-compartmental model with DAS 2.0 software (China Pharmaceutical University). The equation of bioavailability was as follows: absolute bioavailability $=$ AUC of oral administration/AUC of intravenous administration $\times 100 \%$.
Statistical analysis was carried out using SPSS software (version 18.0, SPSS). Independent samples $t$ test was applied in order to analyze the pharmacokinetic parameters between two groups. A $P$ value of $<0.05$ was considered statistically significant.

\section{Result}

Selectivity. Figure 2 illustrates UPLC-MS/MS chromatograms of blank plasma, blank plasma samples spiked with hirsutine,

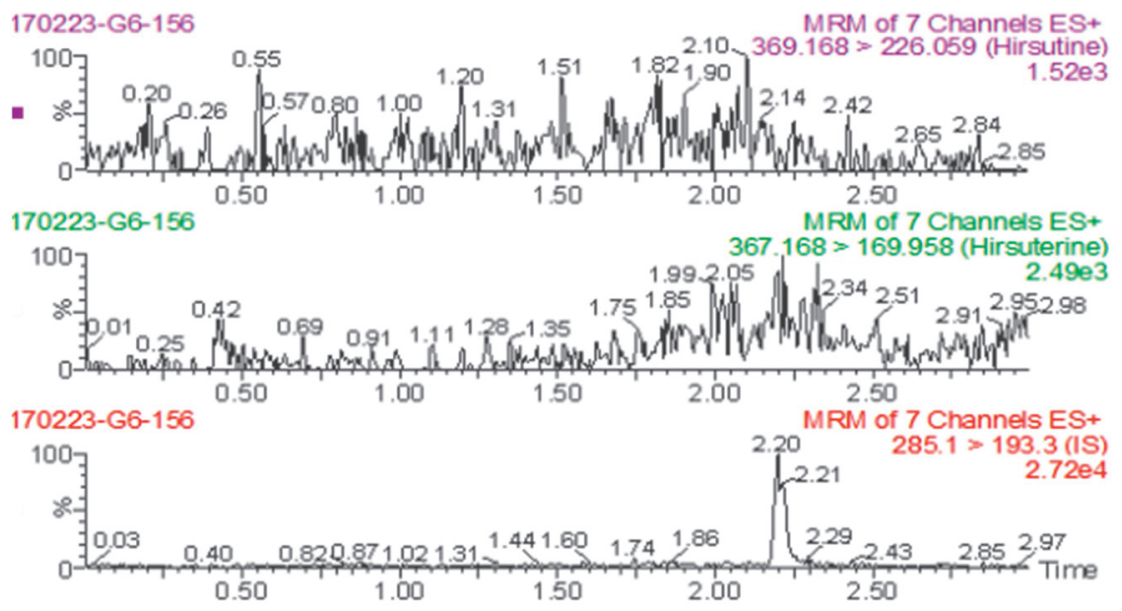

a
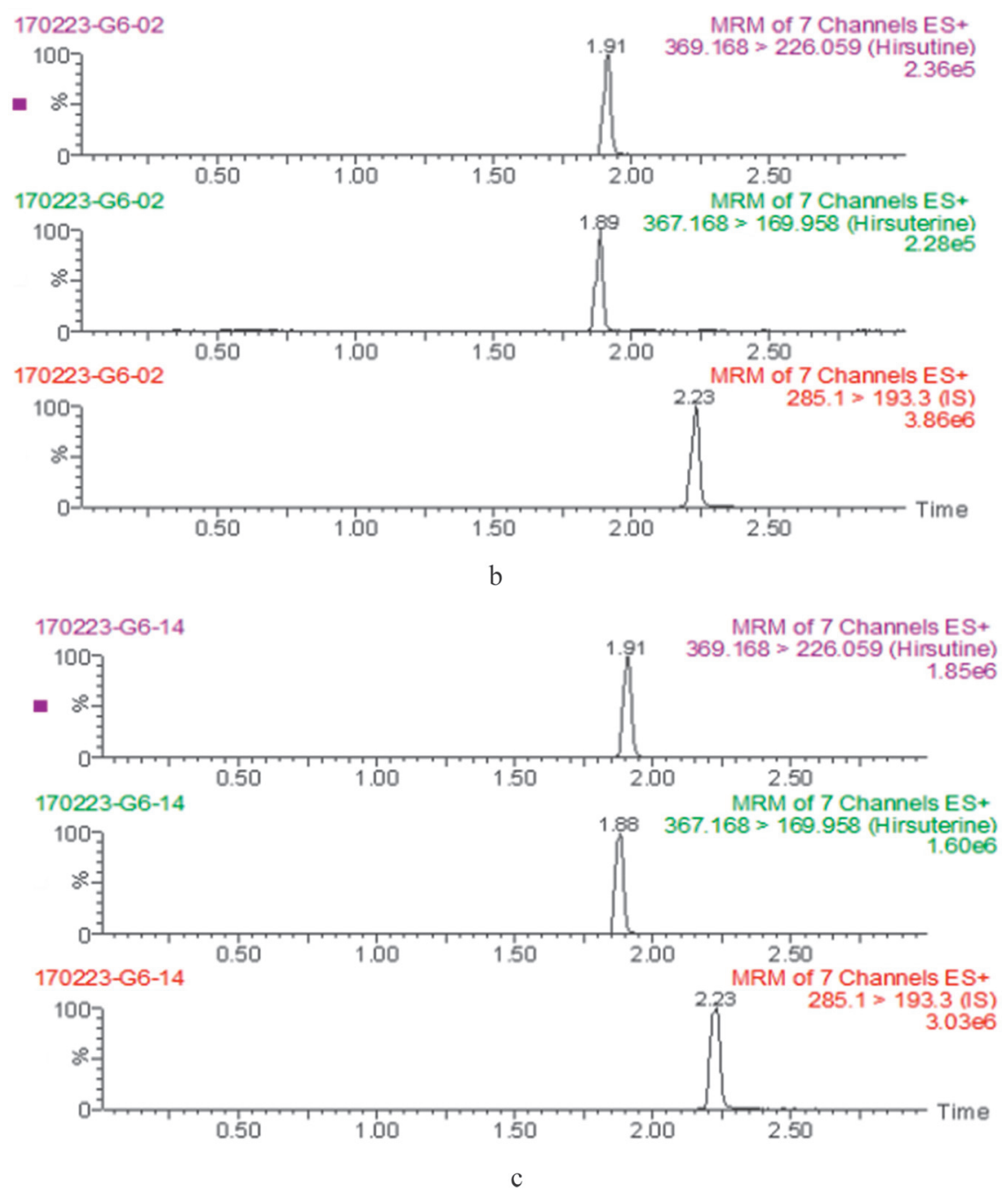

Figure 2. UPLC-MS/MS chromatograms of blank plasma samples (a), blank plasma samples spiked with hirsutine, hirsuteine and internal standard (b), and a collected plasma sample after intravenous administration (c) 
hirsuteine and internal standard, and collected plasma samples. Retention times of hirsutine, hirsuteine, and diazepam (internal standard) were 1.91, 1.89, and $2.23 \mathrm{~min}$. No apparent impurities and endogenous substances were observed to have interfered with the detection, suggesting good selectivity.

Standard Curve. Concentrations of standard curves of hirsutine and hirsuteine in the plasma were in the range of 1-200 $\mathrm{ng} / \mathrm{mL}$. The standard curve equations were as follows: $\mathrm{Y} 1=0.00832 \mathrm{X} 1+0.00741, r=0.9992 ; \mathrm{Y} 2=0.00730 \mathrm{X} 2+$ $0.00696, r=0.9993$; where Y1 represents the peak area ratio of hirsutine to internal standard, X1 represents the hirsutine concentration in plasma, $\mathrm{Y} 2$ represents the peak area ratio of hirsuteine to diazepam, and $\mathrm{X} 2$ represents the hirsuteine concentration in plasma.

The lower limit of quantitation (LLOQ) for hirsutine and hirsuteine in plasma was $1 \mathrm{ng} / \mathrm{mL}$ (signal to noise ratio 12), precision was below $12 \%$, and accuracy was in the range of $85-115 \%$. Limit of detection (LOD) of them was $0.2 \mathrm{ng} / \mathrm{mL}$ (signal to noise ratio, 3).

Precision, Accuracy, Recovery, and Matrix Effect. As shown in Table 1, RSDs of intra-day precision were below $6.1 \%$ at

Table 1. Precision, accuracy, and recovery of hirsutine in plasma $(n=6)$

\begin{tabular}{|c|c|c|c|c|c|c|}
\hline \multirow[t]{2}{*}{$\begin{array}{l}\text { Concentration } \\
(\mathrm{ng} / \mathrm{mL})\end{array}$} & \multicolumn{2}{|c|}{$\begin{array}{l}\text { Precision } \\
\text { (CV\%) }\end{array}$} & \multicolumn{2}{|c|}{$\begin{array}{c}\text { Accuracy } \\
(\%)\end{array}$} & \multirow[t]{2}{*}{$\begin{array}{c}\text { Recovery } \\
(\%)\end{array}$} & \multirow{2}{*}{$\begin{array}{c}\text { Matrix } \\
\text { effect } \\
(\%)\end{array}$} \\
\hline & Intra-d $c$ & ter- & ntra-das & ter-day & & \\
\hline & & & & & & \\
\hline & & & & & & \\
\hline 190 & 6.1 & 6.0 & 104.8 & 95.4 & $89.6 \pm 5.6$ & $04.9 \pm 6$ \\
\hline
\end{tabular}

Table 2. Precision, accuracy, and recovery of hirsuteine in plasma $(n=6)$

\begin{tabular}{lccccccc}
\hline $\begin{array}{l}\text { Concentration } \\
(\mathrm{ng} / \mathrm{mL})\end{array}$ & $\begin{array}{c}\text { Precision } \\
(\mathrm{CV} \%)\end{array}$ & & \multicolumn{2}{c}{$\begin{array}{c}\text { Accuracy } \\
(\%)\end{array}$} & $\begin{array}{c}\text { Recovery } \\
(\%)\end{array}$ & \begin{tabular}{c} 
Matrix \\
effect \\
\cline { 2 - 3 }
\end{tabular} & \multicolumn{2}{c}{ Intra-day Inter-day } & Intra-day Inter-day & & & $(\%)$ \\
\hline 2 & 4.2 & 6.8 & & 98.6 & 92.3 & $84.2 \pm 6.5$ & $106.0 \pm 7.6$ \\
45 & 2.4 & 5.2 & & 96.3 & 94.8 & $87.6 \pm 4.3$ & $108.6 \pm 5.6$ \\
190 & 5.9 & 7.7 & & 104.2 & 101.5 & $95.2 \pm 4.2$ & $99.6 \pm 3.7$ \\
\hline
\end{tabular}

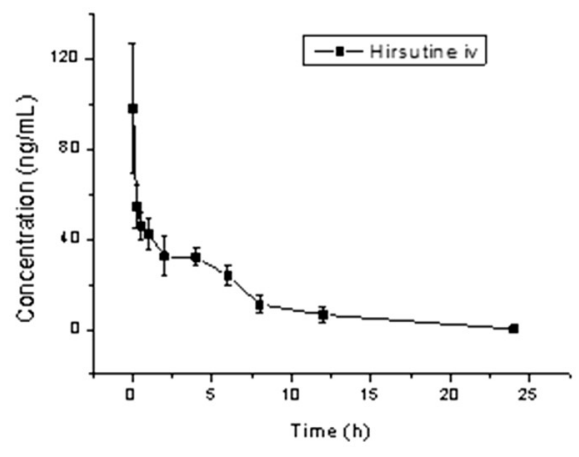

a

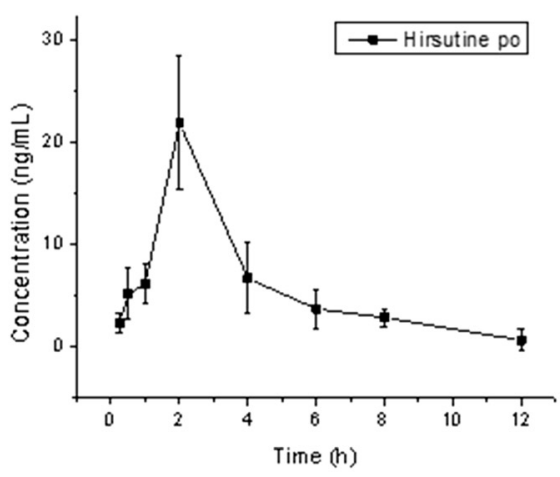

QC samples of hirsutine, and those of inter-day precision were below 6\%. Accuracy ranged between 92.8-104.8\%, average recovery was higher than $83.5 \%$, and the matrix effect was between $101.6 \%$ and $104.9 \%$. As shown in Table 2, the RSDs of intra-day precision were below $5.9 \%$ at QC sample of hirsuteine, and those of inter-day precision were below $7.7 \%$. The accuracy range was between $92.3 \%$ and $104.2 \%$, average recovery was above $84.2 \%$, and the matrix effect was between $99.6 \%$ and $108.6 \%$.

Stability. Variation and RSD of hirsutine and hirsuteine stored at different conditions (room temperature for $2 \mathrm{~h}$, $-20{ }^{\circ} \mathrm{C}$ for 30 days, and freezing-thawing cycles for three times) were $\pm 12 \%$ and $<15 \%$, respectively, suggesting that they were very stable.

Pharmacokinetic Study. Figure $3 \mathrm{a}$ and $3 \mathrm{~b}$ illustrates hirsutine and hirsuteine concentrations versus time after intravenous administration, and Figure $3 \mathrm{c}$ and $3 \mathrm{~d}$ shows the curves after oral administration. Tables 3 and 4 show the main pharmacokinetic parameters analyzed via non-compartment model. The bioavailability of hirsutine and hirsuteine was $4.4 \%$ and $8.1 \%$, respectively, and CL was significantly lower than that of the oral administration. These results demonstrate that hirsutine and hirsuteine were poor absorption.

Table 3. Pharmacokinetic parameters of hirsutine and hirsuteine after intravenous administration

\begin{tabular}{lccc}
\hline Parameter & Unit & $\begin{array}{c}\text { Hirsutine } \\
(1.0 \mathrm{mg} / \mathrm{kg})\end{array}$ & $\begin{array}{c}\text { Hirsuteine } \\
(1.0 \mathrm{mg} / \mathrm{kg})\end{array}$ \\
\hline $\mathrm{AUC}_{(0-t)}$ & $\mathrm{ng} / \mathrm{mL}^{*} \mathrm{~h}$ & $322.9 \pm 53.8$ & $173.3 \pm 21.9^{\mathrm{b}}$ \\
$\mathrm{AUC}_{(0-\infty)}$ & $\mathrm{ng} / \mathrm{mL}^{*} \mathrm{~h}$ & $324.1 \pm 54.2$ & $176.1 \pm 19.7^{\mathrm{b}}$ \\
$\mathrm{MRT}_{(0-t)}$ & $\mathrm{h}$ & $5.0 \pm 0.8$ & $3.1 \pm 0.2^{\mathrm{b}}$ \\
$\mathrm{MRT}_{(0-\infty)}$ & $\mathrm{h}$ & $5.0 \pm 0.8$ & $3.4 \pm 0.4^{\mathrm{b}}$ \\
$t_{1 / 2}$ & $\mathrm{~h}$ & $2.6 \pm 0.7$ & $4.1 \pm 1.9$ \\
$\mathrm{CL}$ & $\mathrm{L} / \mathrm{h} / \mathrm{kg}$ & $3.1 \pm 0.5$ & $5.7 \pm 0.6^{\mathrm{b}}$ \\
$\mathrm{V}$ & $\mathrm{L} / \mathrm{kg}$ & $11.9 \pm 3.2$ & $34.9 \pm 19.5^{\mathrm{a}}$ \\
$C_{\text {max }}$ & $\mathrm{ng} / \mathrm{mL}$ & $97.9 \pm 28.8$ & $72.5 \pm 14.3$ \\
\multicolumn{2}{c}{ Compared with hirsutine group, a is $P<0.05$ and b is $P<0.01$, as } \\
\multicolumn{2}{c}{ indicated by the statistical analysis $t$ test. } \\
\hline
\end{tabular}

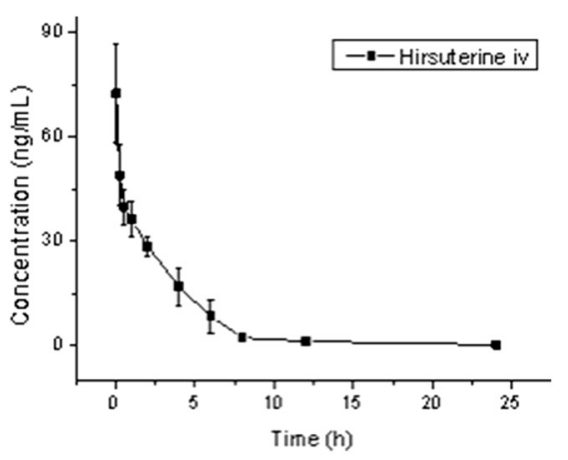

b

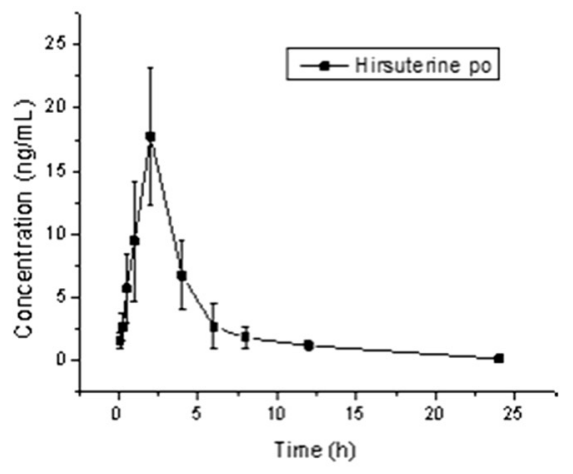

d

Figure 3. Plasma concentration versus time curve of hirsutine and hirsuteine 
Table 4. Pharmacokinetic parameters of hirsutine and hirsuteine after oral administration

\begin{tabular}{lccc}
\hline Parameter & Unit & $\begin{array}{c}\text { Hirsutine } \\
(5.0 \mathrm{mg} / \mathrm{kg})\end{array}$ & $\begin{array}{c}\text { Hirsuteine } \\
(5.0 \mathrm{mg} / \mathrm{kg})\end{array}$ \\
\hline $\mathrm{AUC}_{(0-t)}$ & $\mathrm{ng} / \mathrm{mL}^{*} \mathrm{~h}$ & $70.8 \pm 17.8$ & $70.3 \pm 19.4$ \\
$\mathrm{AUC}_{(0-\infty)}$ & $\mathrm{ng} / \mathrm{mL}{ }^{*} \mathrm{~h}$ & $71.9 \pm 17.7$ & $71.7 \pm 19.7$ \\
$\mathrm{MRT}_{(0-t)}$ & $\mathrm{h}$ & $3.6 \pm 0.6$ & $4.4 \pm 0.9$ \\
$\mathrm{MRT}_{(0-\infty)}$ & $\mathrm{h}$ & $3.8 \pm 0.8$ & $4.8 \pm 0.7$ \\
$t_{1 / 2}$ & $\mathrm{~h}$ & $1.8 \pm 0.5$ & $3.5 \pm 0.9^{\mathrm{b}}$ \\
$\mathrm{CL} / \mathrm{F}$ & $\mathrm{L} / \mathrm{h} / \mathrm{kg}$ & $73.2 \pm 18.3$ & $74.0 \pm 20.1$ \\
$\mathrm{~V} / \mathrm{F}$ & $\mathrm{L} / \mathrm{kg}$ & $189.4 \pm 79.0$ & $359.0 \pm 102.5^{\mathrm{a}}$ \\
$C_{\max }$ & $\mathrm{ng} / \mathrm{mL}$ & $21.9 \pm 6.6$ & $17.8 \pm 5.4$
\end{tabular}

Compared with hirsutine group, a is $P<0.05$ and b is $P<0.01$, as indicated by the statistical analysis $t$ test.

\section{Discussion}

The application of UPLC-MS/MS for the quantitative determination of hirsutine and hirsuteine was faster and more sensitive than a traditional HPLC. The detection time took only $4 \mathrm{~min}$ for the plasma, which saved significant time and cost $[25,26]$. The precision, accuracy, recovery, and matrix effect of the established UPLC-MS/MS method complied with the requirements of pharmacokinetic research for hirsutine and hirsuteine [27-30]. Furthermore, the LLOQ of hirsutine and hirsuteine $(1 \mathrm{ng} / \mathrm{mL})$ was relatively low, which is very helpful to measure the low concentration at the final time point.

Electrospray ionization (ESI) mass spectrometry positive and negative selection was often evaluated in the methodology [31]. It has been found that the ESI positive ion mode was more sensitive than the negative ion mode. The UPLC-MS/MS method was used to separate endogenous interfering substances from hirsutine, hirsuteine, and internal standard as much as possible according to the retention time [32-34]. A good chromatographic peak and retention time could be obtained by using mobile phase acetonitrile (containing $0.1 \%$ formic acid) and gradient elution. The selection of internal standard was also very important. Here, we compared some compounds, which were used as internal standards, including diazepam, carbamazepine, bupivacaine, and lidocaine. Finally, diazepam was selected because it had a similar retention time and ionization mode as hirsutine and hirsuteine.

Prior to UPLC-MS/MS analysis, it is very important to remove the protein and potential interference factors initiate the method [35-37]. As a solution for protein precipitation, acetonitrile has good extraction efficiency and an acceptable matrix effect. Wu et al. [15] used $1 \mathrm{mmol} / \mathrm{L}$ ammonium hydroxide to alkalify the rat plasma and then extracted the drug via ethyl acetate. After drying, the drug was redissolved prior to injection $(5 \mu \mathrm{L})$. Direct protein precipitation via acetonitrile was faster and simpler than the method of $\mathrm{Wu}$ et al. (liquid-liquid extraction). Although acetonitrile diluted the drug concentration in the plasma, the LLOQ was $1 \mathrm{ng} / \mathrm{mL}$, which is still more sensitive than the method by Wu et al. $(2.5 \mathrm{ng} / \mathrm{mL})$.

So far, Wu et al. [15] have reported the pharmacokinetics of rhynchophylline and hirsutine in plasma after oral administration using UPLC-MS/MS. Kashia et al. [16] have studied the pharmacokinetics of hirsutine and hirsuteine following oral administration of Yokukansan based on LC-MS/MS. However, none of these studies reported the pharmacokinetics of hirsutine and hirsuteine administrated via intravenous administration. In this study, the UPLC-MS/MS detection method was built to investigate the pharmacokinetics of both drugs in rats via intravenous or oral administration, based on which bioavailability of both drugs was calculated.

Table 3 indicates that, after intravenous administration, the pharmacokinetic behaviors of hirsutine and hirsuteine differed in rats. AUC and MRT of hirsutine were significantly higher than those of hirsuteine $(P<0.01)$. The $\mathrm{CL}$ of hirsuteine was significantly higher than that of hirsutine $(P<0.01)$, as was $\mathrm{V}(P<0.05)$. The different chemical structure of hirsutine and hirsuteine may be reflected in the pharmacokinetic behaviors. Table 4 shows that, following oral administration, AUC, MRT, $C_{\max }$, and CL of hirsutine and hirsuteine have no significant differences. The $t_{1 / 2}$ of hirsuteine was significantly higher than that of hirsutine $(P<0.01)$, and $\mathrm{V} / \mathrm{F}$ of hirsutine was significantly lower than that of hirsuteine $(P<0.05)$. As shown in Tables 3 and 4, AUC and $\mathrm{V}$ of intravenous administration were significantly higher than those of oral administration. The bioavailability of hirsutine and hirsuteine was reported for the first time, $4.4 \%$ and $8.21 \%$, respectively.

\section{Conclusion}

Here, we established a sensitive and fast UPLC-MS/MS method to measure hirsutine and hirsuteine concentrations in plasma. The linearity range was $1-200 \mathrm{ng} / \mathrm{mL}$, LOD was $0.3 \mathrm{ng} / \mathrm{mL}$, and the run time was $4 \mathrm{~min}$. We successfully used this method for the investigation of the pharmacokinetics hirsutine and hirsuteine via intravenous or oral administration, and the bioavailability was $4.4 \%$ and $8.1 \%$. The analysis of main pharmacokinetic parameters of oral and intravenous administration indicated that hirsutine and hirsuteine had a poor absorption after oral administration.

Acknowledgments. This study was supported by grants from Wenzhou Science and Technology Bureau (Y20140741, Y20140236, and Y20170699), Zhejiang Provincial Natural Science Foundation of China (LY17H200003).

\section{References}

1. Ndagijimana, A.; Wang, X. M.; Pan, G. X.; Zhang, F.; Feng, H.; Olaleye, O. Fitoterapia 2013, 86, 35-47.

2. Zhang, J. G.; Geng, C. A.; Huang, X. Y.; Chen, X. L.; Ma, Y. B.; Zhang, X. M.; Chen, J. J. Eur. J. Mass Spectrom. 2017, 23, 11-21.

3. Li, Y. L.; Yang, W. Q.; Zhu, Q. J.; Yang, J. G.; Wang, Z. BioSci. Trends 2015, 9, 237-244.

4. Qi, W.; Yue, S. J.; Sun, J. H.; Simpkins, J. W.; Zhang, L.; Yuan, D. J. Asian Nat. Prod. Res. 2014, 16, 876-883.

5. Ho, T. Y.; Tang, N. Y.; Hsiang, C. Y.; Hsieh, C. L. Phytomedicine 2014, 21, 893-900.

6. Tang, N. Y.; Lin, Y. W.; Ho, T. Y.; Cheng, C. Y.; Chen, C. H.; Hsieh, C. L. Evidence-Based Complementary Altern. Med. 2017, $2017,9732854$.

7. Hsu, H. C.; Tang, N. Y.; Liu, C. H.; Hsieh, C. L. Evidence-Based Complementary Altern. Med. 2013

8. Pan, H. Q.; Yang, W. Z.; Zhang, Y. B.; Yang, M.; Feng, R. H.; Wu, W. Y.; Guo, D. A. Anal. Bioanal. Chem. 2015, 407, 6057-6070.

9. Lu, W.; Yang, F.; Wang, S. Acta Chromatogr. 2012, 24 643-651.

10. Li, S. P.; Cheng, X. M.; Wang, C. H. J. Ethnopharmacol. 2017, 203, $127-162$.

11. Cheng, H. S.; Ton, S. H.; Kadir, K. A. Phytochem. Rev. 2017, 16, 159-193.

12. Wang, X.; Zheng, M.; Liu, J.; Qiao, Z.; Liu, W.; Feng, F. Xenobiotica 2017, 47, 479-487.

13. Ge, Z.; Xie, Y.; Liang, Q.; Wang, Y.; Luo, G. Evid. Based Complement. Alternat. Med. 2014, 2014, 167253.

14. Cai, J.; Lin, C.; Ma, J.; Hu, L.; Lin, G.; Wang, X. J. Chromatogr. Sci. 2014, 52, 661-665.

15. Wu, Y. T.; Lin, L. C.; Tsai, T. H. Biomed. Chromatogr. 2014, 28, 439-445.

16. Kushida, H.; Fukutake, M.; Tabuchi, M.; Katsuhara, T.; Nishimura, H. Ikarashi, Y.; Kanitani, M.; Kase, Y. Biomed. Chromatogr. 2013, 27, 1647-1656.

17. Wang, X.; Zheng, M.; Liu, J.; Huang, Z.; Bai, Y.; Ren, Z.; Wang, Z.; Tian, Y.; Qiao, Z.; Liu, W.; Feng, F. J. Ethnopharmacol. 2017, 209, 175-183.

18. Zhao, L.; Zang, B.; Qi, W.; Chen, F.; Wang, H.; Kano, Y.; Yuan, D. Fitoterapia 2016, 111, 49-57.

19. Gai, Y.; Chen, H.; Liu, W.; Feng, F.; Xie, N. J. Chromatogr. B: Anal. Technol. Biomed. Life Sci. 2014, 972, 22-28

20. Wang, W.; Luo, S.; Chen, Y.; Li, B.; Hattori, M. Anal. Sci. 2016, 32, 705-707.

21. Ma, J.; Cai, J.; Lin, G.; Chen, H.; Wang, X.; Wang, X.; Hu, L. J. Chromatogr. B: Anal. Technol. Biomed. Life Sci. 2014, 959, 10-15.

22. Liu, M.; Su, X.; Li, G.; Zhao, G.; Zhao, L. J. Chromatogr. B: Anal. Technol. Biomed. Life Sci. 2015, 1006, 8-15.

23. Ai, Y.; Wu, Y.; Wang, F.; Ma, W.; Bian, Q.; Lee, D. Y.; Dai, R. J. Mass Spectrom. 2015, 50, 567-577.

24. Health, U.D.o.; F. Human services; C.f.D.E. Drug Administration; C.f.V.m. Research Fed. Regist. 2001, 66, 206-207.

25. Fang, B.; Bao, S.; Wang, S.; Chen, M.; Chen, B.; Su, K.; Wen, C.; Zhou, Y.; Wang, X.; Jin, Y. Biomed. Chromatogr. 2017, 31. 
26. Wang, J.; Zhao, T.; Kong, J.; Peng, H.; Lv, P.; Li, J.; Cao, X.; Zhang, S. J. Chromatogr. B: Anal. Technol. Biomed. Life Sci. 2017, 1061-1062, 270-274.

27. Jiang, Y.; Zhou, H.; Su, K.; Xu, M. Z.; Chen, B. B.; Chen, D. X.; Wen, C. C.; Wu, B.; Luo, X. H.; Wang, X. Q. Lat. Am. J. Pharm. 2016, 35, 2261-2266. 28. Cai, J. Z.; Huang, Z. Z.; Chen, X. L.; Xu, R. A.; He, H. Z.; Lin, C. L.; Lin, G. Y.; Wang, X. Q. Lat. Am. J. Pharm. 2012, 31, 388-393.

29. Bao, S. H.; Geng, P. W.; Yang, S. P.; Liu, Z. Z.; Lin, Y. Y.; Ma, J. S.; Wen, C. C.; Lin, G. Y.; Zou, R. M. Int. J. Clin. Exp. Med. 2016, 9, 6309-6315.

30. Lin, G. Y.; Ma, J. S.; Lin, C. L.; Hu, L. F.; Wang, X. Q. J. Liq. Chromatogr. Relat. Technol. 2014, 37, 2506-2514.

31. Zhang, Q.; Wen, C.; Xiang, Z.; Ma, J.; Wang, X. J. Pharm. Biomed. Anal. 2014, 90, 134-138.
32. Ye, W.; Chen, R.; Sun, W.; Huang, C.; Lin, X.; Dong, Y.; Wen, C.; Wang, X. J. Chromatogr. B: Anal. Technol. Biomed. Life Sci. 2017, 1060, 144-149.

33. Gullick, D. R.; Mott, K. B.; Bartlett, M. G. Biomed. Chromatogr. 2016 30, 772-789.

34. Yang, X. K.; Ma, Y. J.; Li, N.; Cai, H. J.; Bartlett, M. G. Anal. Chem. 2017, 89, 813-821.

35. Wang, S. H.; Wu, H. Y.; Huang, X. L.; Geng, P. W.; Wen, C. C.; Ma, J. S.; Zhou, Y. F.; Wang, X. Q. J. Chromatogr. B: Anal. Technol. Biomed. Life Sci. 2015 990, 118-124.

36. Ma, J. S.; Wang, S. H.; Huang, X. L.; Geng, P. W.; Wen, C. C.; Zhou, Y. F.; Yu, L. S.; Wang, X. Q. J. Pharm. Biomed. Anal. 2015, 111, 131-137.

37. Wen, C.; Zhang, Q.; He, Y.; Deng, M.; Wang, X.; Ma, J. Acta Chromatogr. 2015, 27, 81-91. 